TITLE: PLASMA AND ELECTRICAL DIAGNOSTICS FOR PROCYON EXPERIMENTS

AUTHOR(S)

H. OONA, B. G. ANDERSON, J. C. COCHRANE, C. E. FINDLEY J. H. GOFORTH, A. E. GREENE, H.-W. KRUSE, J. V. PARKER, AND D. G. RICKEL

SUBMITIED TO

EIGHTH IEEE INTERNATIONAL PULSED POWER CONFERENCE

SHERATON HAKBOR ISLAND (EAST) HOTEI.

SAN DLEGO, CALIFRONIA

JUNE 17-19, 1991

\title{
DISCLAIMER
}

\begin{abstract}
This report wa prepured as un acuourt of work uponsored by an agency of the Uniled Sinte Government. Neither the United Stuten (juvernment nor uny ajency theroof, nor any of their employees, makes any warranty, expreas or implied, of asoumes any lesul liability or responsibility for the accuracy, completeneas, or usefulness of any infurmation, apparalus, producl, or process dimeluned, or represents that iss use would not infringe privulely owned rights. Refer. ence herein to any specific commercial product, process, or cervice by irade name, Irademark, manufacturer, of otherwise doci nut necesuarily constitute or imply its endonement, recommendation, of favorilig by the United Stales (iovernment of any agenty thereor. The views and opinions of authorn expresed herein do not necessorily slate or reflect those of the Unitod Siate (jovernment or any agency thereof.
\end{abstract}

$$
\text { Jul. O' } 1991
$$




\section{PLASMA AND ELECTRICAL DIAGNOSTICS FOR PROCYON EXPERIMENTS*}

H. Ooni, B. G. Anderson, J, C. Cochrane, C. E. Findley,

J. H. Goforth, A. E. Grecne, H. W. Kruse, J. V. Parker, and D. G. Rickel

Los Alamos National Laboratory

Los Alamos, New Mexico $\mathbf{8 7 5 4 5}$

\section{Introduction}

The aim of the 'lrailmaster series of experiments is to generate an intense source of soft $x$-rays by imploding a thin $(2300 \AA)$ aluminum cylinder.' The present scheme incorporates a plasma flow switch for the final pulse shaping and requires careful diagnostic analysis. The emphasis of this work is to transfer the energy to the load area and to understant the dynamics of the plasma flow switch. ${ }^{2}$ The experiments are carried out at LANL in two facilities. Laboratory experiments that an:swer questions about the details of the plasma flow switch are done on the 1.5-MJ Pegasus capacitor bank. The higher energy experiments (Procyon series) utilize explosive pulsed power aystems and are conducted at the Ancho Canyun firing site. It is the latter set of experiments that will eventually supply an $x$ ray radiation source at the megajoule level. At the present time, the emphasis of the Procyon experiments is to deliver enerky from the generator to the plasma flow switch and the load area. The details of these experiments are given in other papers at this conference. ${ }^{3,4}$

In order to characterize these experiments one needs to diagnose the driver performance and the dynamics of the plasma and power flow in the plasma flow switch region. The difficulty of experinents in which high current, high voltage, and high explosive are combined, leads to severe problems. Many of the diagnostics are unique and untested. Since only a limited number of experiments are done during a year, the effori is to maximize the information per shot. The aim in this report is to present some of the diagnostic techniques used in the adverse Trailmaster environment.

\section{The Load Region}

The vacuum power flow region of the the Procyon experiment is shown in fik. I and it extends from the closing switch to the and of the plasma gun. It includes the anodized radiation baffles, the wirc array, the plitina gun, and implosion load region. 'The switch plasma is generated by the wire airay ay current is transferred from the generator to the wires and the JX'l forces move it along the annular gun barrel to the implosion lond. The wire array and the barrier foil combination produces $150 \mathrm{mg}$ of swilch plasma. The wire array is all intrichle wenving of 2-mil-diam aluminum wires as shown in lig. 3 and is designed to give a $1 / R^{2}$ mass dependence, and $R$ represents the ridial distance from the center of the plasinn gun. The present series of P'rocyon experiments will not include the cylindrical lond foil because the goal is to successfully transfer the power to the lond area an deacriber in other papers. 1,2:3

The radiation lastles were tented to minimize the probabil. ity of radiation-induced flashover at the vacuum dielectric interface. A iso, hie radiation characterintics of the baffles need to be known for modifications and optimization of the power how to the load. Flashover lor teflon, which is used for a dielectric interfare, in about $60 \mathrm{\mu J} / \mathrm{cm}^{2}$. We have measured transmission with a pulsed xenon (600-J) lamp and an optical multichannel analyzer (OMA). 'This has shown altenuation of around $10^{7}$ or that about $10 \mu \mathrm{J}$ of spectrally integraled radiation in thr range of 300 to $600 \mathrm{~nm}$ geth to the dielectric vacuum interface. This level of endiation is acceptable and no problems were observed in the l'rocyon experiments. The flahover is also func tion of the npectral dintribution or the temperature of the plasmin pro. dierd by the wire array. In the Inteet Procyon experiment the plama cemperelure of the of the whre array was measured juat

This work was supported by the US Depertinent of Finergy. after the wires burst. The temperatuie was determined from a spectral fit to the blackbody distribution, and the temperature measured was aboul $5 \mathrm{ev}$.

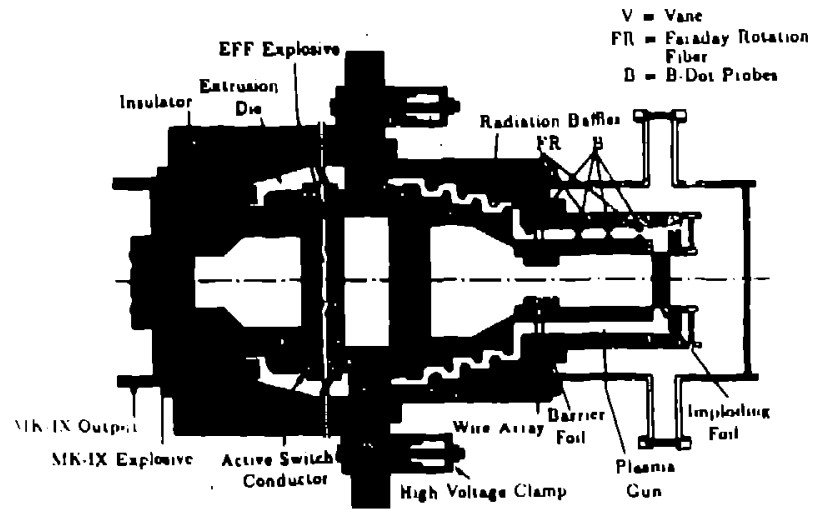

Fig. 1. The components of the Procyon experiment. The radiation baffles, wire array, and barrier foil along with the implosion load area are shown. The location $\dot{B}$ and Faraday rotation probes are indicaled.

\section{Eower Flow Diagnostics}

Several diagnostic techniques are used to measure the the power flow to the load end of the L..periment. Current is measured with Rogowski coils, faraday rotation systems, and $\dot{B}$ probes. The Rogowski and $\dot{B}$ dala are transferred over fiberoptic links that have been instrumental in minimizing ground loops. The Faraduy rotation syatems arc intrinsically frec of electronic noise but have suffered from mechanical shocks, which are the main cause of data loss with Faraday rotation systcus. We rely heavily on accurale current measurements with Rogowski coils and Faraday rolation systems and correlate the dats againat each other. Even though $\dot{B}$ probes can be uscd to measure currents, they measure localized fields and are affected by plasmas and, therefore, are mainly used for plasma velocity and thickness measurements. We normalize the $\dot{B}$ data to appropriately located Rogowski and Faraday rotation sensor data and usc the information to deduce the amount of -urrent flowing and switched in the plasma flow switch. In the pinma flow switch experiments, a scrics of ib probes are placed along the outside and inside electrudes of thr switch channel as shown in Figs. 1 anrl 2 , and they record the arrival time of the plasma as cach probe registere the current an the plamins passes.

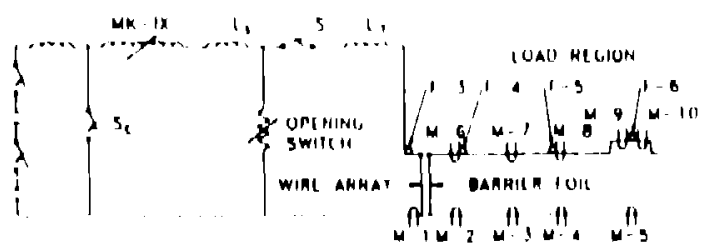

Fig. 2. 'The electrical circuit for the Procyon experiment. "The gencrator, closing and opening awilclies nre ohown. The plasina gun and luad area are ahown to indicate the positions of the sensorm. 'The planme puaition is detected ly $\dot{B}$ probes as it panses the sengor.

The 13 proben ere fabricaled from eolld copper coax ca. ble with the center wlre made Intu a loop and noldered to the uuler copper shell. The aroe of the loopi are epproximaloly $13 \times 10^{\circ} \mathrm{m}^{2}$. The B loop lo embedded ln epoxy inoide a fused allice lube. These probes are extremely rucsed and work 
vell in our environment. Each probe is calibrated by referencng it to a known loop area with a pulsed current source and $n$ this manner the effective loop areas are determined for each ne.

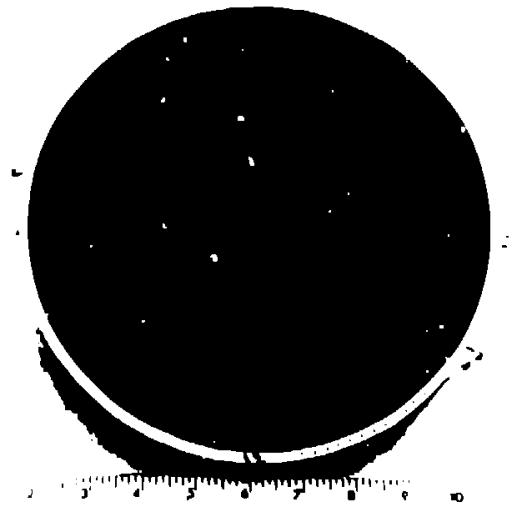

Fig. 3. The wire array. This is the source for the plasma in the slasma fow switch. The pattern is to simulate a $1 / R^{2}$ mass Jependence. The engle, wire size, and the angular step size of he wire positions determine the mass dependence.

Figure 4 a shows integraled $\dot{B}$ data for the probes on the sutside plasma chamnel wall and Fig. 4b shows data for the nside wall. The data for the load region are also included in Fig. $4 \mathrm{~b}$ for one of the Procy an experiments. The probe data or the outside wall have be en normalized to the current that $N$ as observed above the wir array with the Rogowski coils and Faraday rotation probes. V/c can determine the plasina velocty from this data by obs trving the time of the initial rapid ignal onset for each prob:. The velocity of the switch plasma Jetermined in this manne: is $2 \mathrm{~cm} / \mu \mathrm{s}$ between probes $\mathrm{m}-2 \mathrm{t}$ and $\eta-3$ and $5.2 \mathrm{~cm} / \mu \mathrm{s}$ betwe $n$ probes $m-3$ and $m-5 ?$. Id the plasma hickness was estimated o be a maximum of $\sim 5 \mathrm{~cm}$ by the time $t$ reaches the load regic $x$. The same analysis was done for the lata from the inside wi.ll of the gun barrel and the load area We find, for the probe: at their conjugate locations, the velocty to be $2 \mathrm{~cm} / \mu \mathrm{s}$ an, $4.8 \mathrm{~cm} / \mu \mathrm{s}$, respectively. The plesma, herefore, moved in $\mathrm{tl}$ a barrel as a reisonably uniform annular "washer." Also, we ne tice that the rurrent switching to the load area, as indicated b! probers $\mathrm{m}-9$ alld m-i0 was simulaneous but small, and not a same magnitude. The faraday rotation signals in lig. 5 also shon lower currents (significantly less than $100 \%$ ) in the load, sut still higher than the B probes indicate. The fararlay rotal un probes do not reach peak current and are probably alfec ad by ritler mechanical damage or intense adiation that me difies the characteristics of the fiber. Fiven hough the Farad ay probes ara more accurate and not plagued ay local plasma inomalies, they sre, nevertheless, subject to linanges in birefr uperere raused by mechanical effects.

liaraday ro' ation ficld sensors are oxtremely valuable where sround loops al d electrical noise ran severely distort the data. Figure 6 illuat ates the aystem: used at LANL for the Pro. :yon exprime ite. 'i'ha Abers in the experimental setups are protected by , lastic tubing, IR'IV, Torr seal, or other epox. es, which pr vide prote-tion from shocks and IVV light. A beam of linez ily polarized IleNe $(632.8 \mathrm{~nm})$ light is transmitbed througin $f$ in sensor to a recording alation where the rolation of the plane of polarization in measured. Ilalf-Wave retardinlion platen or userl to rotale the polarization direction at the liber entran a and at the analyzer. Following development by

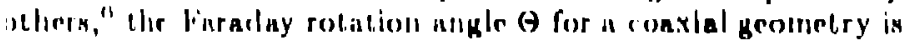
$\theta \quad V^{\prime} \int_{0}^{b} B d x$. $V^{\prime \prime}$ in lle Verdert conatant for the malerial, $H$ in the $n$ ngnetie fleld atrength, and $J$, in the path length in lie field. cecordinl: lo Amperea $\ln w, \quad\left(1 / \mu_{0}\right) \int \| \cdot d x$, and here $I$ in lice currellt croming the aurface bounded ty the line integral id, therelore, $\theta$ a $V^{\prime} \mu . l$. A reault from the shol to diven in $f$ ig. 7 and it is abvious that the fringe are reasonably casy to count early in time but at late times when rapid current changes are taking place and where current reversals are encountered the situation gets difficult. Usually, two detectors are set to record the same signal with a 90-phase difference. The resulting signal will be quadrature coded, making possible the detection of signal reversals.

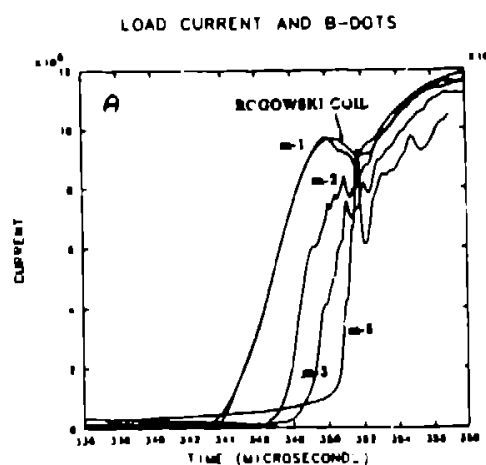

- DoIs insioe channel

Fig. 4. a) The $\dot{B}$ data from the probes on the outside channel. Signals are observed as the plasma passes the probes. The probes currents are normalized to Rogowski coil data. The $\dot{B}$ probes ase muinly used for plasma velocity measurements and thickness. The velocity is determined from the probe location and the sudden onset of probe current. b) The $\dot{B}$ data from the inside wall of the plasma-flow switch. The data are normalized to data from the outside wall. The onset limes from both data sets indicate the the annular plasma was a reasonably uniform. "washer."

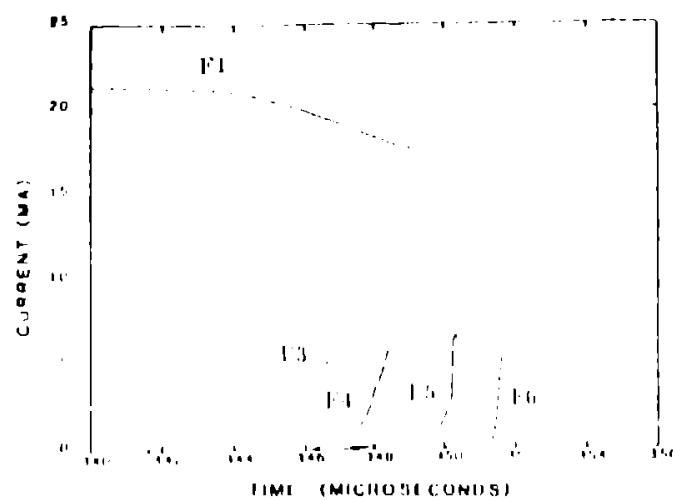

Fig. 5. Faraday rotntion yignals for Procyon experiment (PSS3). The generator and plasma-flow switch currento are shown. li-1 shows the generator current. F-3 in the current measured at the radiation batlles. The current in the plasma gun and lond urea are given by F-A, $l-5$, and $F-6$. F-6 shows the current that is switched into the load.

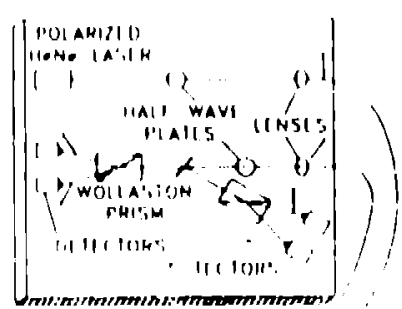

Fig. $\theta$. T'he Faraday rolation oystem on the plasmaHow swltch. The optica and the lond region are shown. A licNe laser trannmitn polarized light that oncircles the current path. Half-wave plates at the entrance and exit of ther flber align the polarization. The Wollaston priamo are heed (o) provide measurements of both the alne and conine of the rotntion angle. 
The sensitivity of the fiber is determined by the Verdet constant and for most of our experiments this sensitivity is $0.6818 \mathrm{MA} /$ cycle, i.e., the polarization changes through one cycle as the current changes $0.6818 \mathrm{MA}$. For accurate current measurements of less than $1 \mathrm{MA}$, the number of fiber turns are increased, and in some cases up to 50 turns have been used with a sensitivity of $0.014 \mathrm{MA} /$ cycle. In cases where the magnetic field changes very rapidly, 3 lower sensitivity $m$.s be desirable and we have used systems with a different laser wavelength $(850 \mathrm{~nm})$ to give a sensitivity of $1.15 \mathrm{MA} /$ cycle.

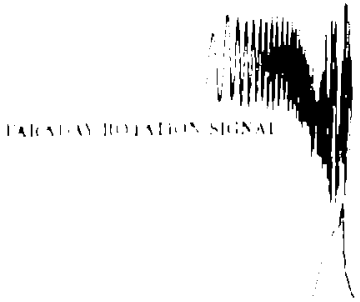

Fig. 7. Example of Faradiy rotation signal from a Procyun experiment. The top curve shows the liaraday rotation signal. The bottom curve shows current. The fringes are counled and multiplied by the Verdet constant lo give the current. For rapidly changing currcnls the resolution is changed so that fringes can be counted.

\section{Radiation Diagnostics}

Even though the emplasis of the Procyon series of experiments has he'en to transfer power to the load region, the need to diagnose the radiation from the up-coming foil implosion tests needs (o) be addressed. The generator and switch in the these experiments are explosively driven and the vacuum implosion chamber and the diagnostics do not survive the blast. "Thr radiation combe: from the plibsma flow switch and the foil implesion reguns. It is necessary to monitor different phase's of each process. In the plasma flow switch we desire to monitor the intiation of the wire array and the subseguent motion of the plabmat down the gun barrel. Doring, the foil implosion pro.

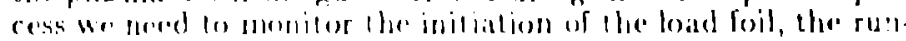
in, and lhermalization. The diagnesties for these experiments include fileered $x$-ray dishles, filtered holometers, time-rosolved imaging camerats, lime-resolved, wr-visible and $x$-ray spectromelers, and pinhole cimerats. In Chis paper we will discuss some of these terhanques and show data obtained from P'egasus and other related experiments.

Visilhe imaging has been done evith two different lypes of cameras: lie hikh pressure hase driven robting mirror cam-

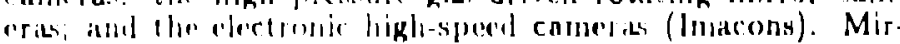

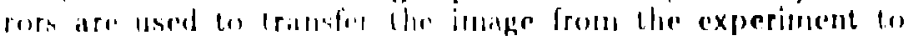

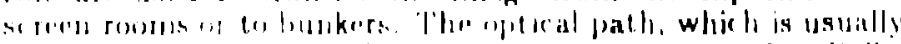

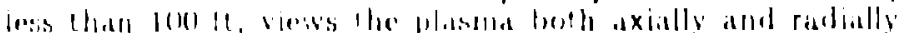

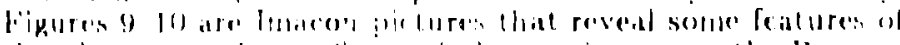

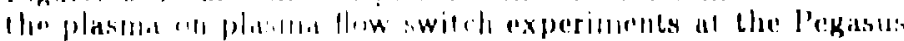
caplatilus hitlk.

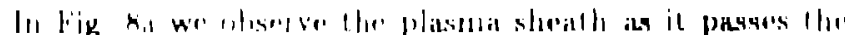

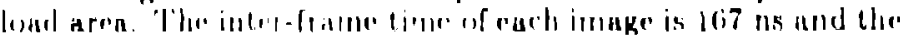

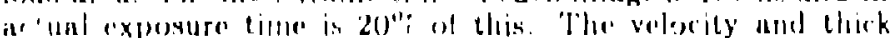

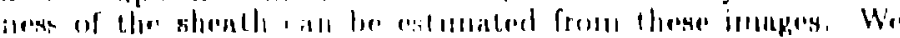

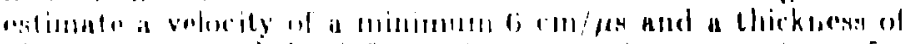

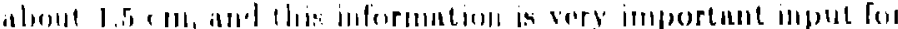

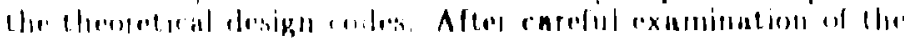

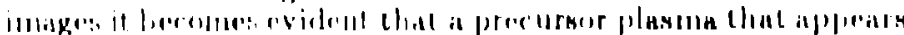

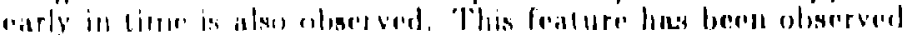

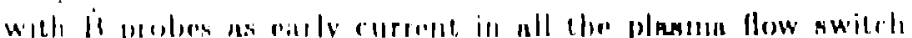

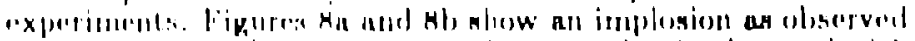

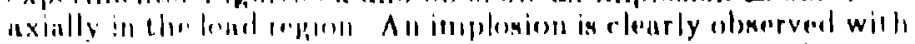

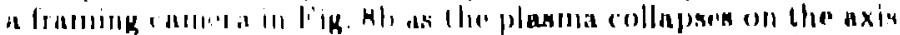

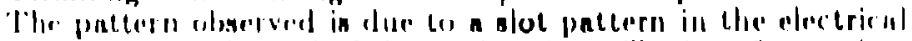
gidde plane a! the end of the lond regton. The interframe time in this experiment in 100) na. Simbiarly, an implooion in chenerved with a atreak carriein (Fig. Mc) an the plaome moven Loward thro axis and the light from the plasma generates a parabolic shape as it accelerates to its collapse. Estimates of the final implosion velocity from the streak camera data were $18 \mathrm{~cm} / \mu \mathrm{s}$.
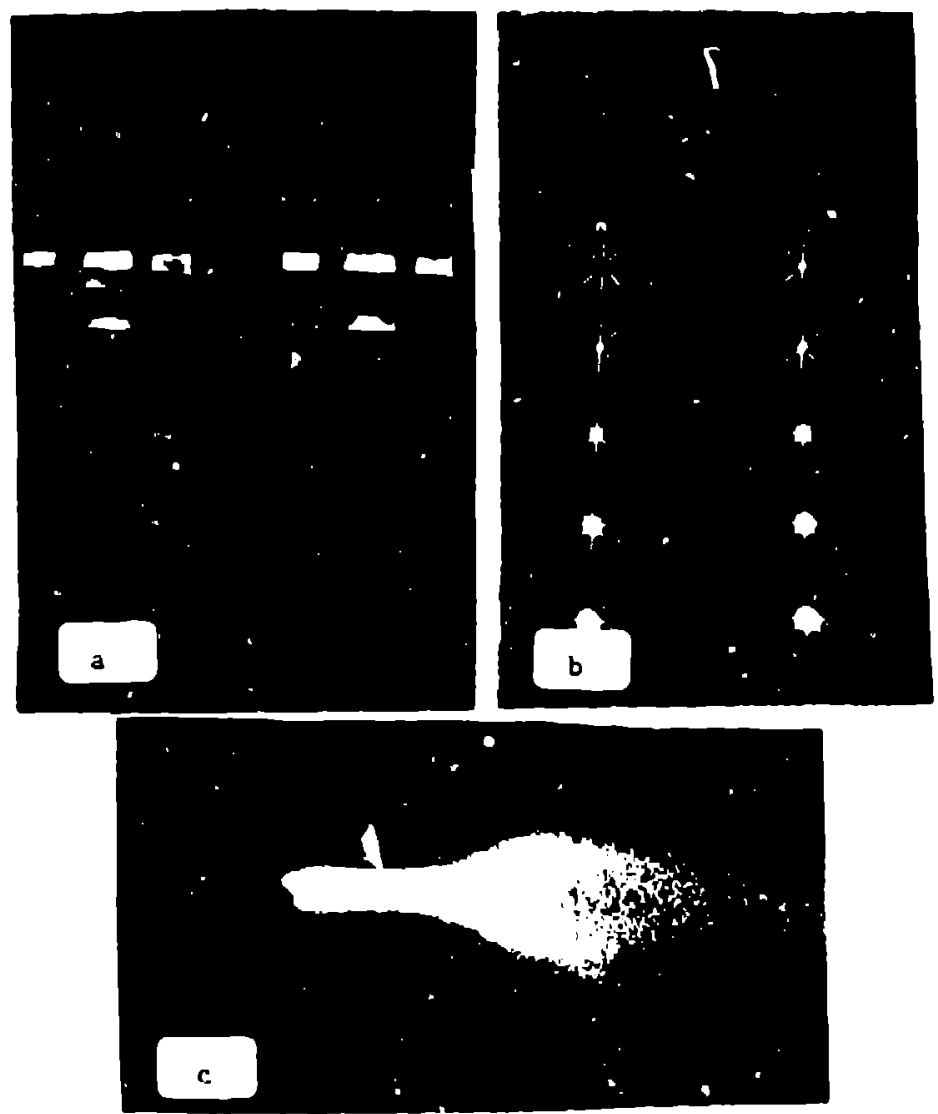

Fig. 8. a) Iladial view of plasma on Pegasus capacitor bank experiment. The images shown are taken 167 ns apart and exposure time is about $34 \mathrm{~ns}$. the timing ulternates from left to right and down. The plasma moves up in each image. We notice early in time the front edge of a precursor and a neries of waves of plasina. The main platsma is observed ay 1 ice oright images during several frames. Histimates of the plasma velocity were $6 \mathrm{~cm} / \mu$ s and a thickness of $1.5 \mathrm{~cm}$. b) Axial view of a plasma pinch in the load area. The pattern is due to a slotled clectrical glide planc. It is clear when plasma reaches :he center. Interframe time in this figure is 100 ns. e) A streak camera p cture of a pinch. As lie plusma implodes and acceltaz'es, a p.rabolic image is observed. late in time the planma begins to expand. At finch time the plasma velocity was calculaterd to be aluout $16 \mathrm{~cm} / \mu \mathrm{s}$.

$X$ rey imaging and spertiroscopy diagnentics are difficule to field in the adverse envirenuments. Thes" diagnostica nend lo be located in the vacumm syntem and in the vichity of high explosives and, therefore, need to be fabricaled in such a way that they i an withotand the explosive nhocks and be recoverable. filin is the minin recording medium for these instruments. Af ter the experiment, thene dingnostics need to be recovered and filu processed. ligure 9 shows an $x$-ray pinhole camera opectrometer combination Shat hos berin nuccennfuliy uned. This chtners in built irsides anc-in.-thick alocel casing, is vacuum

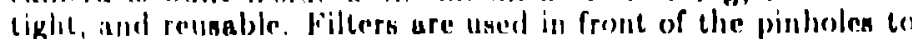
only transmit the $x$-rays. A shutcer merhanism (either aprina leaded or deteriator driven) blorks the atray light after the expriment and prior to recovery. Figure lon shown the raw dala of all $x$-ray pinch from the langunn experimenta. Image rllhamement las improved the pinch region in the photograph an neell in Fin. 10h and a computer determined density prolile is shewn inl lige. 10k. In this picture the dimeneion of the maln "blois" of the pitel in 2-man wide with " height or about $17 \mathrm{cmm}$.

There is a noed to masure the letiperature of the implo sion at pinch time. For this purpue filtered $x$-ray diodes (XKI) and bolomelers are uned and the dala Atled lo a Plancklan 
masler experiments are modified versions that were originally developed at $\mathrm{AFWL}^{7}$ and at Sandia Laboratories, ${ }^{8}$ The one used at I,ANL is a four channel filtered system. The filters and detector foil are chosen to satisfy the conditions of an experiment (approximate temperature). In most of our experiments, the detector foil is $1-\mu 1 n-t h i c k$ nickel mounted on a fused silica substrate. The bolometer is biased with $40 \mathrm{~A}$ about $8 \mu$ s prior to the critical event (pinch). When radiation hits the bolometer foil the temperature of the foil and, therefore, the resistance is changed. This resistance change, along with the current flow in the foil, generates a voltage that is related to the energy deposited in the foil. On one of the latest plasma switch Pegesus experinents we obtained 19.2-kJ total energy deposited into 4- $\pi$ steradians in this experiment. The spectral range of these data covers from about $70 \mathrm{ev}$ to $3 \mathrm{kev}$. The differentiated data gave the power for the imptusion and the peak power was about $5 \times 10^{10} \mathrm{~W}$

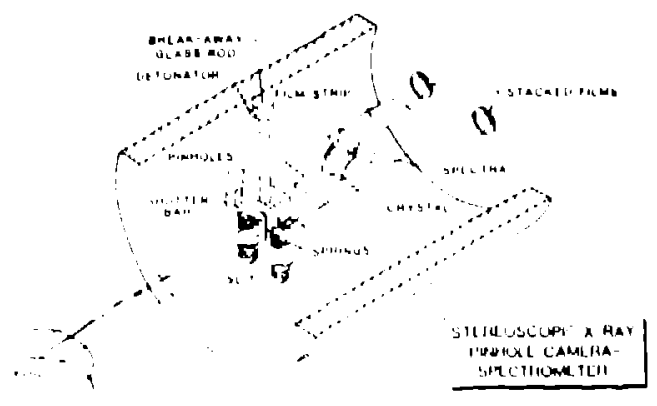

Fig. 9. 'The $x$-ray pinhole canera/spectrometor combination. this camera has been re-used in several experiments. The two inlages can give a stereoscopic picture of the pinch or they can be used with different filtering. the spectrometer is designed to be usable with a variely of $x$-ray crystals. A shutter mechanism closes the system to stray light after the experiment.

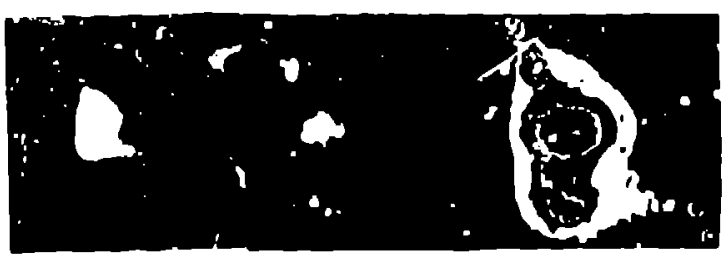

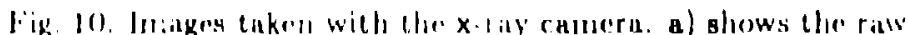

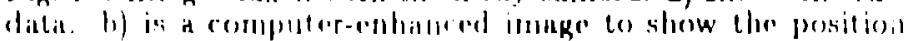

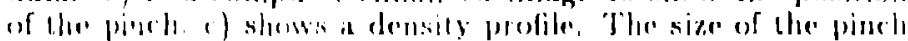

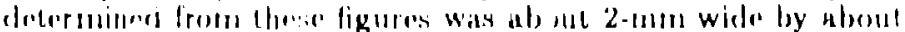
17.mIn high.

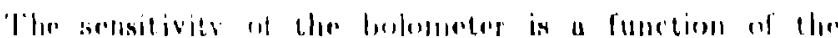

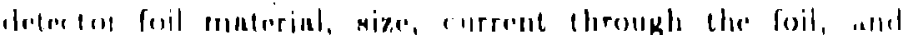

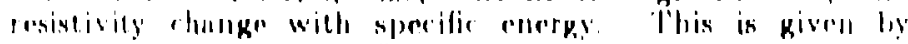

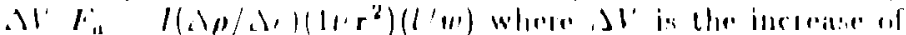

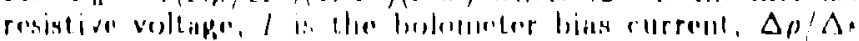

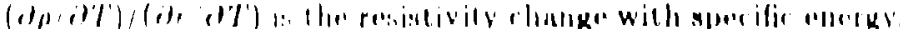

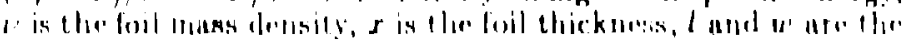

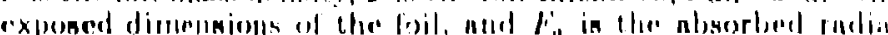

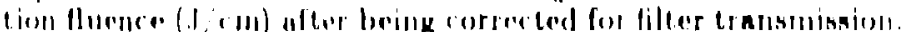

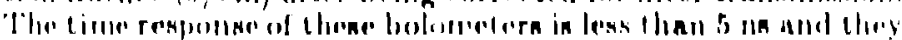

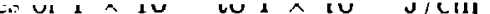
They can operate at Huences up to the point where the foil begins to ablate.

\section{Conclusions}

Over the time period of several years through various phases of the Trailmaster program, numerous diagnostic techniques have been developed and modified. We have demonstrated that the diagnostic techniques have been successfully fielded in the adverse environments. Other diagnostic developments are in progress including time-resolved, high-resolution $x$-ray spectroscopy and imaging. Improvements are being made in electrical diagnostics and the increased use of fiber optic links has significantly enhanced the nuality of the electrical data. Noise pickup and ground loop problems encountered on previous experiments have virtually been eliminated.

\section{Acknowledgeine'its}

Wo vish to give special commendation to Vivian Gurule for her infinite patience in fabricating the intricate wire arrays and the $\dot{B}$ probes. Many thanks go to Dennis Herrera and the Pegasus crew with the help for the successful Procyon experiments. Also, special thanks must be given to Janet Neff for the excellent typing and preparation of this manuseript.

\section{Referuncess}

11 W. I. Baker, G. Bird, J. S. Bulf, C. Boyer, C, J. Clorse, S. K. Colfey, D. Conlo, D. W. Conley, J. F. Davis, J. II. Degnan, D. Dietz, M. F Fresi, J. D. Graham, S. L. Gonzalez, K E. Hackel, D. J. Hali, J. L. Holmes, E. A. Lopez, W. F. McCullough, R. E. Peterkin, D. W. Price, R. E. Reinovsky, N. F. Roderick, S Seiler, P. J. Turchi, S.W.R. Warren, and J. M. Welby, "Multi-Megampere Plasma Flow Switch Driven hiner Implosions," in Megagauss Technology and Pulsed Power Applications, C. M. Fowler, R. S. Caird, and D. J. Erickson, eds. Plenum Press, pp. 653-662, 1986.

(2) A. B. (ireene, R. L. Howers, J H. Brownell, J. H. Goforth, 11. Oona, 1). L. Peterson, D). (i. Rickel, and D). I. Weiss, "Computational Modeling of the 'Trailmaster P'rocyon System," this conference

(3) J. H. Golorth, II. Oona, J. II, Brownell, A. E. Greene, H, W. Kruse. I. R. Lindemull, S. P. Marsh, J. V. Parker, R. E. Roinovsky, D), (i. Rickell, and P. J. Turch:i, "Procyon lixperiments Utilizing lixplosively-formed Fuse Opening Switches," this conference.

(1) I. G. Rickol, I. R. Lindemuth R. Li. Reinovs'xy J. II (Boforth, A. E. Girenene, II, W. Kense, Il. Oona, J. V. Parker, and P'. J. 'Turchi, "P'ro y. le lixperiment Utilizing foll- Puse" (Opening Switches," this conference.

[5] C. L, linloe and R, $V$, (illenubach, "Microscopic nud Macroscopie Material Property Filfects on UltravioletLaser-linduced Flashover of Angled linsulators in Vacuum,"

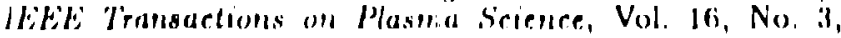
Junc ight.

|S| L, R. Vereser, R. S. Cinird, (: M. Fowler, and I). J. Firick-

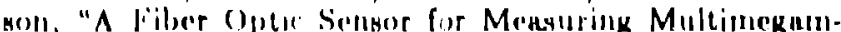
pere Currents lirom Plux (imprension Cenerators," in Proceedings of SI'll: The Ie ternational Society for (op.

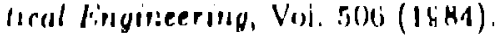

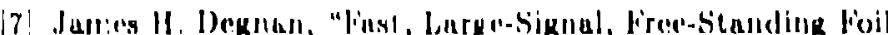

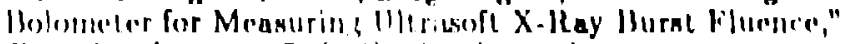
Rea. Sict. Inatrum. BO(10), (). tober 1979.

A Private communitation with Invid Innmeon at, Sinndia Natirilal liaboratories. 